\title{
Emergency Hotline as a Communication Tool in Times of Crisis
}

\author{
Gabriela Socha ${ }^{1}$ \\ ${ }^{1}$ District Headquarters of the Polish Police Forces in Katowice \\ ul. Lompy 19, 44-100 Katowice - Poland
}

\begin{abstract}
For a couple of decades telephone crisis services called hotlines or helplines have been an important instrument in the process of providing help and assistance to people in distress. The idea of providing psychological help and support over the telephone was born of sincere kindness and sympathy of human heart but with time it evolved towards a standardized scientific discipline based on rules and procedures. The paper outlines the history of telephone crisis services and points to their most important functions in contemporary, globalized world.
\end{abstract}

Index Terms - crisis, crisis situation, telephone crisis service, hotline, helpline, trust, intervention.

\section{INTRODUCTION}

Communication is a transfer of data or exchange of information between entities. It is based on individual interpretation of the message and it constitutes a conscious and intentional act. According to Denis McQuail there is a number of levels of social communication: intragroup, intergroup, communication within institutions and organizations, mass communication as well as intrapersonal and interpersonal communication. The intragroup impact takes place within small groups, whereas intergroup communication relates to large groups in which not all the members know or come in direct contact with one another e.g. local communities and associations. In case of organizational communication the roles of senders and receivers are clearly determined, defined and formalized. But the widest process of all is mass communication which is transmitted via mass media: radio, press, television, the Internet. Here many parties participate in exchange of information, as the information reaches nearly every corner of the world. Intrapersonal communication in turn, consists of all kinds of biological reactions to stimuli from within the organism (Gawroński, 2018).

For the purposes of this particular paper interpersonal communication is of key importance. Special attention should be brought to a definition formulated by John Stewart, which

ASEJ - Scientific Journal of Bielsko-Biala School of Finance and Law

Volume 22, No 3 (2018), 5 pages

DOI: $10.5604 / 01.3001 .0012 .7451$

Received: 10 October 2018; Accepted: 15 October 2018 assumes that interpersonal communication is such a type, quality or kind of contact which occurs when people speak or listen in order to maximize what is personal (Stewart, 2009). The author emphasizes that the term 'interpersonal' with respect to communication, goes beyond the communication itself. It means more than just face to face communication as it refers to the type or quality of interpersonal contact, appropriate for many instances of communication, also to a telephone conversation, which, due to obvious reasons, is never carried out face to face.

What is very important is the fact that most people perceive communication as action, which obviously is a very simplified view. This model of communication assumes the existence of the speaker and listeners, always one 'teacher' and one or more groups of 'students'. Transfer of information is in one direction only (if feedback loop is omitted). Interpersonal communication is understood as such contact between human beings which is based on reciprocity. Therefore communication must be treated as interaction, as a process of reciprocal influence. Such approach to communication, to informing, and at the same time expecting feedback, is vital in the context of using emergency line as a tool of communication in crisis situations.

The terms 'crisis' and 'crisis situation' have become increasingly popular lately, even fashionable. One may wonder about reasons for such a career of these terms because crisis has always been present in human life. Maybe it is because people only recently have learned to verbalize, define and openly speak about their problems. Crisis and crisis situation, despite their frequent occurrence, are unique and unrepeatable just as unique and unrepeatable individual human beings are. Taking into account the complexity of processes accompanying crisis and inscrutability of human nature, there is no universal recipe so as to crisis resolution. The paper focuses only on emotional crisis which is something virtually imminent for each human being. It is very typical that one day life beats a person down on the ground, and the other day makes them wake up stronger, richer in new experiences and ready for new challenges. Mental crisis

Regular research paper: Published 20 October 2018

Corresponding author's e-mail: gabrielasocha2@gmail.com

Copyright (C) 2018 This is an open access article distributed under the Creative Commons Attribution CC-BY-NC 4.0 License. 
is a feeling of powerlessness and unpredictability of the future, usually generated by strong mental disturbance, personal loss or closure of a certain phase in life. The characteristic feature of crisis is a strong emotional strain and overwhelming absence of the will to live. Another important aspect of crisis is time. A crisis never goes on forever, it never lasts a long time. It is often assumed that the average duration of crisis is from six to eight weeks after which the process of healing begins provided that the person affected received help. Sometimes external help from not related people is necessary as not everyone is surrounded by loving family, caring and observant friends or understanding superiors and co-workers. These groups of people i.e. family, friends, colleagues are the first instance where assistance should be sought in a crisis situation. Sometimes it is even not necessary to say a word, hints of unusual behavior will instantly be noticed by those who care. But there is a group of people who go through life alone, nobody cares for them, if they do not start crying for help they will sink in loneliness and overwhelming chaos, they may even take others down with them.

\section{MEDIA AND TELEPHONE AS MEANS OF COMMUNICATION}

Telephone is a useful tool which may help to address certain problems of contemporary people. It was invented by Alexander Graham Bell in 1876. At the turn of the centuries the invention was perfected to enable communication between people wherever they are and whenever they want. At this point it should be emphasized that communication becomes medial when it is carried out by means of electromagnetic waves carrying signals whose sending and receiving exceeds the capacity of biological apparatus of human perception or when it is materialized on a carrier. The first type involves transmission media, the second recording media. When the two types merge they become what is known as communications media, understood as the entirety of means of communication. Older media such as press, radio, television are generally referred to as mass media, and the relatively new media such as smart phone or PC are called telematic media (Goban-Klas, 2008).

\section{THE BEGINNINGS OF EMERGENCY HOTLINES}

The founder of the idea of a telephone crisis service was a minister of the Baptist Church Harry Marsh Warren, who in 1906 in the United States opened the first suicide prevention organization 'Save-a-Life League'. It all began during his stay in New York when a young woman in despair contacted him for help. As he was in a hurry he refused to see her, the woman left alone with her problem took tranquilizers and overdosed. Shortly before she died she told rev. Warren, who was called to her death bed: "I think maybe if I had talked to someone like you, I wouldn't have done it." Marsh Warren overwhelmed by her death and his failure to deliver help decided to encourage suicidal people to make telephone contact with him. Local press helped to propagate this idea and the venture took off culminating in opening a clinic for suicidal persons called 'Save-a-Life League', the clinic provided not only psychological but also material help.

Further development of telephone crisis services can be attributed to a British Anglican priest Chad Varah, who in 1953 in London founded an organization for those contemplating suicide. The organization was called the 'Samaritans'. Varah began to understand the problems facing the suicidal when he was taking a funeral as an assistant curate in 1935, his first church service, for a fourteen-year-old girl who had taken her own life because she had begun to menstruate and feared that she had a sexually transmitted disease. Varah was devastated by the girl's death and a series of suicides that followed. He vowed at that time to encourage sex education, and to help people who were contemplating suicide and had nowhere to turn. On the church door he put a notice: 'Before you commit suicide, call us'. The idea was picked up by the Daily Mirror newspaper, who coined the phrase 'crisis hotline' which started to be commonly used for any kind of help provided by telephone to people who are helpless, lost, suicidal.

In Poland the first emergency helpline was opened in Gdańsk in 1967. The service, initiated and developed by professor Tadeusz Kielanowski and Grażyna Świątecka, was based on the 'Samaritans' principles, and started to be known as Gdańsk Crisis Hotline 'Anonymous Friend'. The facility was of clearly social character. The attendants on call worked on voluntary bases and they represented different walks of life. The service was a subsection of the Polish Red Cross and the assistants worked from the Red Cross district headquarters. In 1967 professor Adam Bukowczyk from Mental Disease Clinic of Wrocław Medical University set up a more professional hotline with doctors and psychologists available to provide advice and assistance. A year later more hotlines emerged in Bydgoszcz and Torun, next in Warsaw, Lublin and Kraków. In 1970 in Warsaw the first telephone counselling service for children and young people was opened. Two years later, in 1972, Katowice and Olsztyn also had their 'Anonymous Friend' emergency lines. Soon afterwards the Polish Catholic Church opened their hotline services in Poznań, Zielona Góra and Szczecin. In 1983 in Warsaw the first IFOTES (International Federation of Telephone Emergency Services) associated emergency hotline for alcohol addicts was created, and in 1999 the first in Poland Internet emergency service 'Anonymous Friend'.

To increase the quality of services offered by telephone emergency lines, the Polish Council Coordinating Telephone Emergency Services was appointed in Kraków. Moreover, many emergency hotlines joined the International Federation of Telephone Emergency Service (IFOTES). With time the Polish Coordinating Council was transformed into Coordinating Committee with the headquarters in Sopot. In 1990 the Polish Association of Telephone Counselling was appointed with the headquarters in Sopot, the Association brings together assistants working for emergency services all over Poland.

The Polish Association of Telephone Counselling (PTPT) provides support in the following areas:

- prevention, protection and promotion of health and social assistance; 
- helping lonely persons, addicted persons and their families;

- counteracting pathologies and social exclusion;

- supporting people in social and mental crisis;

- protection of human rights and freedoms;

- propagating of voluntary work.

Currently PTPT has about 400 members, the Association is responsible for organizing annual conferences for hotline assistants, they also publish a bulletin of informational and training character under the title "Telefon Zaufania Nasza Gazeta", which is sent to major libraries in Poland. Many Polish emergency hotline services are associated with PTPT and their activity is based on the so called "International IFOTES standards". The most basic and at the same time the most important IFOTES standards include:

- providing access to the telephone hotline to people in distress and crisis;

- listening but restraining from criticism and judgment, kindness;

- absolute discretion concerning what was said during the counselling sessions;

- providing full anonymity of the caller;

- strict avoidance of any religious, political and ideological pressure.

The list below features selected emergency lines functioning in Poland:

- 800120148 - toll free hotline 'Stop the Violence';

- 226199149 - anti-terrorist hotline;

- 116111 - emergency line for children and young people;

- 800121212 - the Children's Emergency Line of the Polish Children's Ombudsman - a service devoted to all the children who need help;

- 801120002 - the Blue Line for victims of domestic violence or for those who possess information about persons experiencing domestic violence in their homes;

- 801199990 - the Polish Emergency Line offering support for drug addicts;

- 226928226 - 24-hour-emergency-line of the National AIDS Centre;

- 801247070 - 24-hour-support-line of the Centre for Missing People ITAKA;

- 116000 - 24-hour-toll-free-number offering assistance when children are missing;

- 801109801 - emergency line of the National Centre of Competences.

\section{JUST DIAL THE NUMBER}

The first step initiating the healing process or the problem solving process is picking up the phone and dialing the hotline number. This very act is a passage from a thought and reflection to concrete steps leading towards solving the problem, it liberates the subconsciousness with which every human being was brought to life. The survival instinct is the most powerful strength of the universe. "It is commonly understood that those who want to talk about their suicidal thoughts and seek help do not really want to die, but still they represent a high risk of suicide" (Kubacka-Jasiecka, 2010). Experts agree that dialing an emergency line number is a 'cry for help', being suicidal is a symptom of emotional crisis, a temporary disturbance of mental stability and not an actual attempt at self-destruction. It should be remembered, that those who turn to the emergency line in their dark moments must feel alienated in the world they live in, they are lonely people who are unable to seek support and counselling in their immediate environment. Not always in their conversation with the counsellor will they articulate their problem but they will send various signals which should be detected by a careful ear of the counsellor. Most 'customers' of helplines are absolutely helpless, they may have been affected by morality crisis, the treadmill of everyday life or they may have got lost direction in the rat race. Every so often they are tormented by the feeling of guilt for not being able to provide their families with appropriate living standards, they experience the so called 'loser syndrome' which is usually enhanced and reinforced by frustrated families who keep raising their expectations. Some callers seek assistance as a result of a life tragedy which tore their world apart, some are worried by the absence of role models in contemporary world or lack of respect for legal norms. Some people call because they feel rejected, alienated from their immediate environment due to their abnormal behavior or just because of their being different. Typical groups of callers are: alcohol and drug addicts, their families, homosexuals, sick people or people whose appearance derogates from what is considered as standard and they are unable to come to terms with their otherness and the fact that certain human reactions will accompany them till the end of their lives. Another group of callers are young people with adolescence problems who cannot find support from their parents, they think they do not fit in with their peers and they lose the will to live. Young people constantly look for ideals but their system of values is frequently re-evaluated and each failure or even unhappy love is elevated to the level of personal tragedy. It happens every so often that the fear of confessing the truth e.g. about unwanted pregnancy or repeating a year at school, is paralyzing and may lead to suicidal thoughts. In recent years the so called online crisis chats have become very popular with young people due to complete anonymity offered by the Internet, however this form of communication unlike the telephone contact is completely impersonal and very shallow.

\section{MAIN FUNCTIONS OF EMERGENCY HOTLINES}

There are three fundamental functions of a crisis helpline: offering support, providing objective information and knowledge, and intervention. With respect to the first function, the caller should be allowed to speak, to ventilate emotions (whatever the problem concerns, difficult external situation or just mere dark thoughts and fantasies) in a friendly, safe and anonymous atmosphere. The fundamental principle of a hotline is that it must offer the possibility to speak to each and every caller, 24 hours a day in absolute anonymity and discretion. The essence of hotline help is based on an assumption that the caller is experiencing a deficit of 'emotional capacity', i.e. he or she is unable to accommodate and bear the overwhelming emotions. Therefore, the assistant must concentrate on active, 
supportive listening. The pre-condition and requirement for a good counsellor is not only the ability to establish and maintain contact, but also the ability to endure and withstand all the difficult emotions of the caller. The counsellor must be able to mobilize all the resources and self-assurance within the caller that can help him/her to overcome the crisis. It is important to break the deadlock and help the caller assume a problem solving attitude. The counsellor should suggest seeing another specialist: a doctor, a lawyer, a therapist, a counsellor, a parent etc., who will be able to provide more professional help than the telephone assistant.

The second function of each crisis hotline is providing information and knowledge so as to possible ways of overcoming the difficulties. Those who decide to turn to a helpline most probably have a deficit of both information and knowledge concerning ways out of their misery. It is the task of the telephone assistant to inform the caller about different forms of professional help, the procedures that must be undertaken etc. The counsellors must dispose of appropriate amount of relevant knowledge and an extensive database available at hand. But still, the most important asset of a good counsellor is the gift of establishing and maintaining contact. If the caller is a child it is important to inform this child precisely how to get to the place where help can be received and to whom they should report.

When it comes to intervention, the counsellor must initiate crisis proceedings with respect to the caller who has found himself/herself in a difficult situation e.g. as the result of violence, accident, suicide attempt, development of mental sickness etc. During intervention phase it is necessary to cooperate with various facilities (e.g. emergency room, hospital, the police, shelter, emergency care unit etc.) or with intervention team who for example will go to collect an abandoned child from the street and place it under professional care. The assistant is responsible for initiating the process of helping the caller who has limited possibilities (external and internal) for self-help and then for monitoring the case until it has been taken over by relevant institutions. The aid provided by helpline operators is critical because it initiates crisis intervention proceedings. The pre-requisite for providing high level of services is well-trained personnel knowing what procedures to apply and when (Jaroszewska, 2001).

Well conducted telephone intervention should fulfill the following conditions:

- the assistant must be fully engaged in the conversation;

- the assistant must keep reassuring the caller;

- the assistant should refrain from making judgements, should encourage the caller to express his/her feelings and emotions openly;

- the assistant should offer the feeling of security, companionship but without taking the responsibility away from the caller;

- the assistant must listen in order to extract the most important problems and issues from the caller;

- the assistant should provide addresses of people and institutions which may help the caller;

- the assistant should offer the caller his/her credentials and offer readiness to cooperate;

- during a conversation with a suicidal caller the assistant is obliged to determine the whereabouts of the caller, make sure that the caller is safe and direct him/her to a crisis intervention center;

- the assistant must motivate the caller to seek direct contact with those who may help as this is so much more effective in terms of security of the person in distress (KubackaJasiecka, 2010).

A big advantage of emergency helplines is the fact that the lines are open non-stop and the counsellor can offer time and attentive ear at any time of night and day. It is not easy for the telephone assistants as they do not see the face of the caller and therefore are unable to notice many important signals resulting, for instance, from body language. They need to listen attentively because the help and support they are going to offer may be of critical importance for overcoming the crisis of the caller. Assistants do not rely entirely on their intelligence and life experience, which in themselves are very important factors. During training sessions they learn to recognize attitudes and thoughts, mainly of suicidal character, symptoms of mental illnesses, but most of all, they learn to listen attentively and speak with friendliness and care typical for a true and caring friend. In practice however, acquiring all these skills turns out to be quite difficult. The main challenges seem to be related to the competences of assistants, the choice of appropriate strategies and intervention procedures but also to the intentions of individual callers. There is always a certain amount of risk involved. But on the whole, any doubts related to the existence and efficiency of telephone help services are quickly outweighed by benefits this type of help brings.

\section{THE MEANING OF TRUST}

Telephone interventions as a tool of psycho-sociological support in emotional crisis, play a very important role in crisis management. But without winning trust of the caller it is not possible to bring any help. Trust is a complex process whose essence is difficult to define. Trust is a specific bond that needs to be established between the caller and the assistant who is at the other end of the line. The bond must be based on the assumption and belief, that by sharing their secrets and weaknesses the caller will not be harmed in any way. The caller must be convinced that by sharing the burden, they will feel better, that by talking the problems over with the assistant they can ease their pain and calm down the troubled mind. Only in an environment based on trust and understanding, the counsellor may offer comfort, hope and assurance that the caller is capable of overcoming the crisis. The essence of trust is contained in an assumption that the person on the other side of the line is eager to help and has competences to offer professional help and counselling. For the very same reasons people seek help from doctors when they are ill. 


\section{CONCLUSIONS}

Even when we do not have enough strength to open our eyes and come out of bed in the morning after a sleepless night, when the world around us lost all his color and seems strange and indifferent, we should still remember that life is worth living. It is difficult to say before the crisis strikes whether we are able to go through it alone or whether we will have to rely on others for help. We do not even know how we will react when we will be offered help. We are not machines but complicated and fragile beings. One day the world may seem beautiful and the future bright, and the next day we are overcome with terrible thoughts and we are just shadows of our usual selves. Fighting a crisis is not easy, if it were the humanity would not have experienced many horrible tragedies. Norway would not have to weep and mourn almost a hundred innocent victims whose lives had ended before they even begun. Everyone may be in need to call an emergency line one day. If not with an own problem maybe with a problem of somebody else. We should keep our eyes open, we must not be blind and indifferent to others! The work of all crisis hotline assistants is very important, it is a therapy in itself for those who are in despair which helps to alleviate or even close a difficult time in life.

\section{REFERENCES}

Gawroński, S. (2018). Media $i$ komunikowanie spoleczne $w$ systemie bezpieczeństwa wewnętrznego. [online] Available at: http://wsiz.rzeszow.pl/kadra/sgawronski [Accessed 4 May 2018].

Goban-Klas, T. (2008). Komunikowanie i media. Komunikowanie i media, p.23.

Jaroszewska, M. (2001). Telefon zaufania dla dzieci. Cztery funkcje telefonu pomagania. Niebieska linia, (3).

Kubacka-Jasiecka, D. (2010). Interwencja kryzysowa. Warszawa: Wydawnictwa Akademickie i Profesjonalne, p.532.

Stewart, J. (2009). Mosty zamiast murów. Warszawa: Wydaw. Naukowe PWN. 